\title{
Elevated survivin expression in peripheral blood mononuclear cells is central to collateral formation in coronary chronic total occlusion
}

\author{
YIGUAN XU, XUERUI TAN, DONGMING WANG, WEI WANG, YUGUANG LI, MIN WU, \\ SONGMING CHEN, YINGE WU and CHUNJIANG TAN \\ Department of Cardiology, The First Affiliated Hospital of Shantou University Medical College, \\ Shantou, Guangdong 515041, P.R. China
}

Received August 8, 2014; Accepted March 9, 2015

DOI: $10.3892 / \mathrm{ijmm} .2015 .2154$

\begin{abstract}
Survivin is essential to angiogenesis and revascularization, but its role in coronary collateral formation remains unclear. The role of survivin in peripheral blood mononuclear cells (PBMCs) of coronary chronic total occlusion (CTO) patients was investigated. Coronary CTO patients $(n=46$; mean age 60.1 \pm 8.5 , male 54.3\%) (CTO group) and normal control patients $(\mathrm{n}=18$; mean age $58.0 \pm 10.0$, male $55.6 \%)$ underwent angiographic collateral vessel grading by Rentrop classification (C0 - C3) and provided peripheral blood between June 2006 and February 2007. Rat hind limb ischemia models were constructed using four equal groups of Sprague-Dawley rats $(n=36)$ : normal control, sham operation, operation and granulocyte macrophage colony-stimulating factor (GM-CSF). PBMC numbers and characteristics, collateral vessels, survivin, CD4, CD8, CD44, vascular endothelial growth factor (VEGF) and intercellular adhesion molecule-1 (ICAM-1) expression were determined using RT-PCR, flow cytometry, immunocytochemistry and western blot analysis. PBMC survivin mRNA and protein expression levels were higher in patients with good collateral circulation $(\mathrm{C} 2+\mathrm{C} 3)$ than in patients with no collateral flow (C0) (all $\mathrm{P}<0.05$ ). Survivin single-positive and survivin and CD8, VEGF and ICAM-1 double-positive percentages were elevated in patients with good collateral circulation compared to those with normal and no collateral flow (all $\mathrm{P}<0.05$ ), consistent with the rat model results, wherein higher survivin levels produced significantly larger and more visible collateral vessels. In conclusion, elevated survivin expression in PBMCs, particularly survivin and CD8, VEGF, and ICAM-1 double-positive
\end{abstract}

Correspondence to: Dr Yuguang Li, Department of Cardiology, The First Affiliated Hospital of Shantou University Medical College, No. 57, Changping Road, Shantou, Guangdong 515041, P.R. China E-mail: menmeno2003@aliyun.com

Key words: collateral vessel, survivin, peripheral blood mononuclear cells, vascular endothelial growth factor, intercellular adhesion molecule-1
PBMCs, may be crucial for good collateral formation in patients with coronary CTO, as confirmed by assessment of a rat model.

\section{Introduction}

Cardiovascular diseases, in particular coronary artery disease (CAD), remain leading causes of mortality in developed countries (1). Coronary chronic total occlusion (CTO) affects up to $18.4 \%$ of all CAD patients and significantly influences cardiac function and outcomes of treatments, such as angioplasty and surgical bypass (2). Coronary collateral circulation (CCC) provides a natural bypass that supplies heart, potentially with therapeutic potential to improve myocardial viability in CAD patients $(1,3)$. Survivin, a unique member of the inhibitor of apoptosis proteins (IAPs) family that exhibits cell cycle-regulated expression peaking at mitosis, has been demonstrated to impact cardiomyocyte replication and apoptosis, providing a potentially promising myocardial regeneration target (4). The role of survivin in peripheral blood mononuclear cells (PBMCs), cells whose gene expression profiles have been linked to CAD severity (5), remains unknown.

The role of survivin in angiogenesis is well documented, particularly in tumor cells (6). It has been demonstrated that survivin is minimally expressed in non-proliferating endothelial cells, but upregulated in newly formed blood vessels (7). Survivin, however, also plays a role in collateral vessel formation, as demonstrated by increasing microvessel density in survivin-positive tumors (8). In CAD patients, survivin influences cardiac function by controlling total cardiomyocyte numbers through its impact of collateral vessel formation and angiogenesis (4). Furthermore, Zwerts et al (9) reported that regulation of endothelial cell survival and maintenance of vascular integrity by survivin are crucial for normal embryonic angiogenesis, cardiogenesis and neurogenesis, demonstrating the importance of survivin in vascularization and revascularization.

In CTO patients, the role of CCC has been widely disputed; however, modern study has generally indicated that well-developed CCC is indicative of severe stenosis (10). When cardiac events occur, such as acute myocardial infarction, the presence of a well-developed CCC can mediate the detrimental effects 
of ischemia on heart tissues, thus preserving left ventricular function, reducing overall infarct size, preventing left ventricular aneurysm and increasing survival (10). Notably, collateral blood flow is often reduced after successful CTO recanalization, as antegrade blood flow is re-established and resistance is increased in collateral vessels (10). Thus, collateral vessel formation may be observed as a marker of stenosis and prognosis in CAD patients.

Altered survivin expression may impact collateral vessel formation, as indicated by Conway et al (11) who showed that survivin was uniquely expressed by microvessels in the peri-infarct and infarct regions 2 days after permanent artery occlusion. Furthermore, using a mouse model with heterozygous deficiency of middle cerebral of the survivin gene (survivin ${ }^{+/}$mice), no alterations in infarct size were apparent (11). As the microRNA signature of PBMCs, including survivin, has been linked to CAD (5), it is likely that these cells also play a role in collateral formation. Furthermore, rising levels of vascular endothelial growth factor (VEGF), an angiogenic and vasoprotective molecule modulated primarily by inflammatory mediators, may also impact collateral formation in CAD patients, and intercellular adhesion molecule-1 (ICAM-1) may impact collateral formation and CAD onset $(12,13)$, although the relationship between these molecules and survivin in PBMCs is unknown. Assessment of survivin levels as well as other molecules in PBMCs may thus be linked with collateral formation.

While the role of survivin in angiogenesis is well documented, much less is known about the distinct role survivin plays in collateral formation during coronary CTO. The present study examined the clinical relationship between PBMC survivin expression and coronary collateral formation in humans and the PBMC signatures associated with collateral formation. Correlations of survivin, VEGF and ICAM-1 expression were also examined in peripheral blood samples from human patients, and these correlations were confirmed in a rat model of hind limb ischemia. These experiments provided a basis for assessment of collateral formation based on PBMC survivin levels, potentially useful in revascularization therapies for CTO and CAD.

\section{Materials and methods}

Study design. A total of 46 coronary CTO patients (mean age $60.1 \pm 8.5$, male $54.3 \%$ ) (CTO group) and 18 patients with normal coronary artery vascularity (mean age 58.0 \pm 10.0 , male $55.6 \%$ ) (control group) were included in a prospective study between June 2006 and February 2007 at the Department of Cardiology of the the First Affiliated Hospital of Shantou University Medical College (China). In addition, an animal model was established using 36 male Sprague-Dawley rats aged 4-5 months and weighing 250-300 g. The rats were randomly divided into four equal groups of 9 rats each, including the normal control, sham operation, operation and granulocyte macrophage colony-stimulating factor (GM-CSF) treatment groups. The study protocol was approved by the Ethics Committee of Shantou University Medical College. Procedures involving experimental animals were performed in accordance with protocols approved by Institutional Guidelines for Care and Use of Laboratory Animals of Shantou University
Medical College, in compliance with the Law of the People's Republic of China on the Protection of Wildlife (2004). The patients provided written informed consent for participation.

Patients. Included patients in the coronary CTO group $(n=46$; mean age $60.1 \pm 8.5$, male $54.3 \%$ ) exhibited i) angiographic studies showing coronary CTO occlusion (>99\% occluded) for $>2$ weeks in any 3 major coronary artery branches, consistent with the diagnostic guidelines of Teeuwen et al (14); ii) measurable collateral flow according to Rentrop classification prior to reopening of the artery, as previously described (15). Patients that presented with other serious illness that potentially affected testing, such as acute myocardial infarction, cancer, pulmonary heart disease and severe renal insufficiency were excluded. Control subjects experienced chest pain and were suspected to have coronary heart disease, although normal coronary artery flow was confirmed by angiography for the patients included in the control group. The study protocol was approved by the First Affiliated Hospital of Shantou University Medical College, Shantou, and all the participants provided written informed consent.

Sample collection. Angiography was performed using the Judkins technique via the femoral approach with 6F guiding catheters as previously described (16). The patients received a bolus of heparin (50 IU/ $\mathrm{kg}$ ), aspirin (100 mg/day), and clopidogrel (75 mg/day) for $\geq 3$ day when percutaneous coronary intervention (PCI) was performed. Approximately $10 \mathrm{ml}$ of peripheral blood was drawn with moderate suction in a $10 \mathrm{sec}$ period using the femoral approach, and angioplasty was continued.

Angiographic grading. Angiograms were assessed independently by two blinded investigators, and in case of disagreement, a consensus was obtained (through consultation). According to the Rentrop classification (15), the angiographically visible diameter of collateral connections was graded as: $\mathrm{C} 0$, no opacification; $\mathrm{C} 1$, filling of artery side branches by collateral vessels without visualization of the epicardial segments; C2, partial filling of epicardial segments by collateral vessels; and C3, complete filling of epicardial segments by collateral vessels. Rentrop C1 was regarded as poor collateral circulation, and Rentrop C2 and C3 were regarded as good collateral circulation.

PBMC isolation. PBMCs were separated by standard density gradient centrifugation using the Ficoll-Paque method (Biochrom, Berlin, Germany), according to the manufacturer's instructions. PBMCs $\left(3 \times 10^{6}\right.$ cells $\left./ \mathrm{ml}\right)$ were then cultured in buffered RPMI-1640 supplemented with $10 \%$ (v/v) heat-inactivated fetal bovine serum (both from Sigma, St. Louis, MO, USA).

Flow cytometry. PBMCs were washed once with phosphatebuffered saline (PBS) solution, fixed in $4 \%$ paraformaldehyde at room temperature for $40 \mathrm{~min}$, and incubated in $0.2 \%$ Triton X-100 (Sangon Corp., Shanghai, China) for $10 \mathrm{~min}$ and $5 \%$ calf serum at $4^{\circ} \mathrm{C}$ for $10 \mathrm{~min}$. PBMCs were then incubated in PBS containing survivin (1:1,000; Novus Biologicals, Inc., Littleton, CO, USA), CD4 (1:100), CD8 (1:100), CD44 (1:100) (all from Boster Biotechnology Co., Wuhan, China), 
VEGF (1:200), and ICAM-1 (1:200; Santa Cruz Biotechnology, Inc., Dallas, TX, USA) antibody overnight at $4^{\circ} \mathrm{C}$. After washing, the PBMCs were incubated in appropriate fluorescein isothiocyanate (FITC) (survivin) and/or Cy3 (CD4, CD8, CD44, VEGF and ICAM-1)-conjugated secondary antibodies. Flow cytometric analysis was conducted using a Coulter Epics XL flow cytometer (Beckman Coulter, Brea, CA, USA), and the percentage of positive cells was calculated.

Immunocytochemistry. Survivin expression in PBMCs was detected by immunocytochemical staining using an Ultravision Detection System (Lab Vision Corporation, Newmarket Suffolk, UK), as previously described (17). Briefly, after blocking endogenous peroxidase activity, PBMCs were incubated for $1 \mathrm{~h}$ at room temperature with rabbit polyclonal antibody to survivin (1:1,000; Novus Biologicals). After washing, the cells were incubated for $1 \mathrm{~h}$ at room temperature with biotinylated goat anti-rabbit IgG (1:10,000; Santa Cruz Biotechnology, Inc., Brea, CA, USA). Nuclei were counterstained with hematoxylin. Three replicates were performed for each sample.

RT-PCR detection of survivin mRNA expression in PBMCs. Total RNA was isolated from PBMCs using TRIzol reagent (British Biocell International, Cardiff, UK). RNA purity was determined using absorbance at 260 and $280 \mathrm{~nm}$ (A260/280), and RNA integrity was verified by $1.5 \%$ agarose gel electrophoresis (Invitrogen, Grand Island, NY, USA). Total RNA was reverse-transcribed into cDNA using RevertAid ${ }^{7 \mathrm{M}} \mathrm{M}-\mathrm{MuLV}$ Reverse Transcriptase and oligo(dT) 18 primer (both from Thermo Scientific, Waltham, MA, USA). Approximately $436 \mathrm{bp}$ of the human survivin region and $612 \mathrm{bp}$ of the $\beta$-actin region were generated by RT-PCR using total RNA $(2 \mu \mathrm{g})$. Primer sequences for survivin were: forward, 5'-ATG GGT GCC CCG ACG TTG-3' and reverse, 5'-AGA GGC CTC AAT CCA TGG-3'. Primer sequences for $\beta$-actin were: forward, 5'-CGC TGC GCT GGT CGT CGA CA-3' and reverse, 5'-GTC ACG CAC GAT TTC CCG CT-3'. Reactions involved initial denaturation at $95^{\circ} \mathrm{C}$ for $3 \mathrm{~min}$ followed by 35 cycles at $94^{\circ} \mathrm{C}$ for $1 \mathrm{~min}$, annealing at $61^{\circ} \mathrm{C}$ for $1 \mathrm{~min}$, and extension at $72^{\circ} \mathrm{C}$ for $1 \mathrm{~min}$ and an additional cycle at $72^{\circ} \mathrm{C}$ for $10 \mathrm{~min}$. $\beta$-actin was used as an internal control. RT-PCR products were subjected to $1.5 \%$ agarose gel electrophoresis, and the abundance of each mRNA was normalized to $\beta$-actin using Image Lab (Bio-Rad, Hercules, CA, USA). Relative mRNA expression was considered to be the optical density (OD) of survivin by the $\mathrm{OD}$ of $\beta$-actin $\left(\mathrm{OD}_{\text {survivin }} / \mathrm{OD}_{\beta \text {-actin }}\right)$.

Western blot analysis. Western blot analysis was performed as previously described (17). Total protein was isolated from PBMCs using TRIzol Reagent (British Biocell International). Proteins were quantified by a Bradford assay. Total protein $(50 \mu \mathrm{g})$ was separated on $12 \%$ sodium dodecyl sulfatepolyacrylamide gel (SDS-PAGE) gels, and electro-transferred to NC membranes (Millipore, Bedford, MA, USA). After non-specific binding sites were blocked with 5\% skim milk for $1 \mathrm{~h}$, the membranes were then incubated in a mixture of Trisbuffered saline and Tween-20 (TBS-T) containing survivin (1:1,000), CD4 (1:100), CD8 (1:100), CD44 (1:100), VEGF (1:200) and ICAM-1 (1:200) antibodies for $2 \mathrm{~h}$ at room temper- ature. After washing, the membrane was incubated in TBS-T containing the appropriate secondary anti-IgG antibodies (1:5,000; Santa Cruz Biotechnology, Inc.) at room temperature for $1 \mathrm{~h}$. The target protein was detected using western blotting luminol reagent (Santa Cruz Biotechnology, Inc.), according to the manufacturer's instructions. Results were visualized by autoradiography using X-Omat autoradiography film (Kodak, Rochester, NY, USA). For protein loading normalization, a similar procedure was performed using a monoclonal antibody against tubulin (1:1,000; Beyotime Institute of Biotechnology, Hangzhou, China) as an internal standard. Three replicates were performed for each sample.

Rat model of hind limb ischemia. Using four groups of 9 rats each (normal control, sham operation, operation and GM-CSF treatment groups) a rat model of hind limb ischemia was constructed, as previously described (18). For operation and GM-CSF treatment groups, the right femoral artery of each rat was ligated directly distal to the inguinal ligament to achieve hind limb ischemia on the right side. Sham operations were performed similarly, but without femoral artery ligation.

The day after surgery, the mice in the treatment group were administered rHuGM-CSF (10 $\mu \mathrm{g} / \mathrm{kg} / \mathrm{day}$; Xiamen Amoytop Biotech Co., Xiamen, China) in $0.9 \%$ normal saline solution by subcutaneous daily for 5 days. The control, sham operation, and operation groups were administered the same volume of $0.9 \%$ normal saline solution. At day 28 after the surgery, the rats were sacrificed by overdose of injected anesthetic drugs (phenobarbital sodium), blood samples were taken by cardiac puncture from each specimen, and postmortem angiography was performed. PBMCs were isolated from blood samples, and the number of cells positive for survivin, CD4, CD8, CD44, VEGF and ICAM-1 were detected by flow cytometry.

Postmortem angiography. Postmortem angiography was performed as previously described (19). Briefly, peripheral vascular tissues were fully expanded to better reveal collateral vessels and then perfused through the descending aorta with PBS containing adenosine (1 g/l) (Bio Basic Inc., Amherst, $\mathrm{NY}, \mathrm{USA}$ ) as a vasodilator for $3 \mathrm{~min}$ at physiological pressure. Vasculature was fixed with $2 \%$ paraformaldehyde in PBS for 5 min, flushed with PBS for 2 min, and infused with $76 \%$ meglumine diatrizoate and $10 \%$ gelatin (1:1) in PBS as a contrast reagent. The contrast reagent was solidified by immersing whole specimens in ice for $5 \mathrm{~min}$. Angiograms were taken at two different angles, resulting in stereoscopic images that were used in 3-dimensional (3D) collateral growth analysis.

Statistical analysis. Data were analyzed using SPSS version 13.0 for Windows (SPSS Inc., Chicago, IL, USA). Data were presented as the means \pm standard deviations (SD). Differences between groups were analyzed by one-way ANOVA and Student-Newman-Keuls (SNK) Games-Howell tests. $\mathrm{P}<0.05$ was considered statistically significant $(\mathrm{P}<0.05)$.

\section{Results}

Baseline demographic and clinical characteristics of experimental and control patients. Of the total 46 patients, no collateral flow was observed in 12 patients $(\mathrm{C} 0)$, poor collateral 

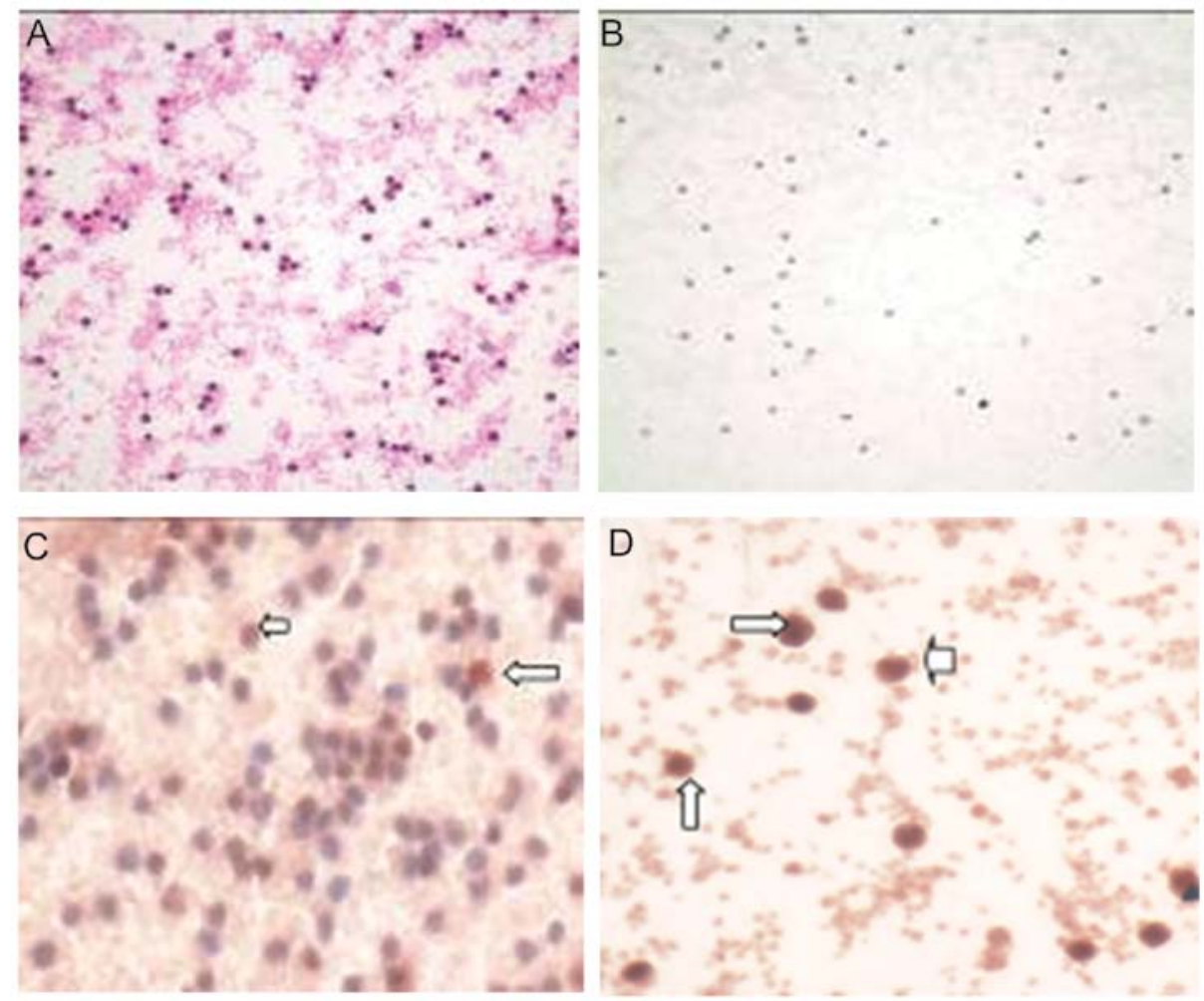

Figure 1. Immunocytochemical staining of human peripheral blood mononuclear cells (PBMCs) showing survivin expression (x400). (A) H\&E staining of PBMCs showing clear and intact nuclei and plasma membranes in $\mathrm{C} 2$ patients. (B) $\mathrm{C} 0$ patients with no survivin-positive cells and without collateral formation (C) Poor collateral formation (C1 patients) with survivin-positive reactions in nuclei and plasma membranes of some cells. (D) Good collateral formation $(\mathrm{C} 2+\mathrm{C} 3$ patients) with survivin-positive reactions in the nuclei and plasma membranes. (C and D) Arrows indicate survivin-positive cells.

circulation was observed in 18 patients $(\mathrm{C} 1)$, and good collateral circulation was observed in 16 patients $(11 \mathrm{C} 2$ patients and $5 \mathrm{C} 3$ patients). No significant differences in baseline demographic or clinical characteristics, including age, gender, cardiovascular risk factors, median duration of occlusion were observed among the coronary CTO and control group patients (P>0.05) (Table I). Notably, all the coronary CTO patients were currently using vasoactive and lipid-lowering drugs, although none of the patients in the control group were on similar medication. Heparin was administered immediately prior to angiography in the coronary CTO and control patients.

Survivin expression in human PBMCs during coronary collateral formation. Immunocytochemical staining indicated that survivin-positive PBMCs were significantly upregulated in patients with good collateral formation, including plasma and nuclear regions (Fig. 1). Similarly, RT-PCR and western blotting indicated that the mRNA and protein expression of survivin in PBMCs was significantly higher in patients with good collateral circulation $(\mathrm{C} 2+\mathrm{C} 3)$ than that in patients with no collateral flow $(\mathrm{C} 0)(\mathrm{P}<0.05)$, although no significant differences were observed between $\mathrm{C} 2$ and $\mathrm{C} 3$ patients ( $\mathrm{P}>0.05)$ (Fig. 2).

CD4, CD8, CD44, VEGF and ICAM-1 protein expression in human PBMCs during coronary collateral formation. Western blot analysis revealed that CD8 and CD44 expression in PBMCs was significantly higher in patients with good collateral formation $(\mathrm{C} 3+\mathrm{C} 2)$ than in patients with poor collateral formation $(\mathrm{C} 1)$, no collateral formation $(\mathrm{C} 0)$, and normal controls (all $\mathrm{P}<0.05$ ) (Fig. 3). CD4 and VEGF expression were also higher in patients with good collateral circulation than in those with no collateral flow (C0) and normal control patients (all $\mathrm{P}<0.05)$. However, this result was non-significant between patients with good collateral circulation $(\mathrm{C} 3+\mathrm{C} 2)$ and poor collateral circulation $(\mathrm{C} 1)(\mathrm{P}>0.05)$. ICAM-1 expression was higher in patients with collateral formation than that in normal control patients (all $\mathrm{P}<0.05$ ). However, this result was nonsignificant among good collateral $(\mathrm{C} 3+\mathrm{C} 2)$, poor collateral $(\mathrm{C} 1)$, and no collateral $(\mathrm{C} 0)$ groups $(\mathrm{P}>0.05)$.

Flow cytometric analysis of survivin single- and double-positives in human PBMCs. Flow cytometric analysis revealed that the percentages of survivin and CD44 single-positive PMBCs, survivin and CD8 double-positive (survivin + CD8), survivin and VEGF double-positive (survivin + VEGF), and survivin and ICAM-1 double-positive (survivin + ICAM-1) PBMCs were significantly higher in patients with good collateral formation than those in the normal controls and those with no collateral formation $(\mathrm{C} 0)($ all $\mathrm{P}<0.05)$ (Fig. 4 and Table II). Percentages of survivin + CD8 and survivin + VEGF double-positive PBMCs were significantly higher in patients with good collateral formation than those in the normal control and with no collateral formation (C0) (all $\mathrm{P}<0.05)$.

Postmortem angiography in rat models and PBMC survivin expression correlation. In rat models, macroscopic collateral arteries were visible after right femoral artery ligation (operation and GM-CSF treatment groups) (Fig. 6). 
Table I. Baseline clinical and demographic characteristics for CTO patients and normal controls.

\begin{tabular}{|c|c|c|c|c|c|}
\hline \multirow[b]{2}{*}{ Variables } & \multirow[b]{2}{*}{$\begin{array}{l}\text { Normal control } \\
\qquad(\mathrm{n}=18)\end{array}$} & \multicolumn{3}{|c|}{ Rentrop classification ${ }^{\mathrm{a}}$} & \multirow{2}{*}{ 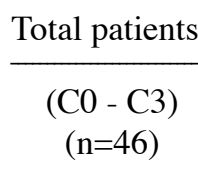 } \\
\hline & & $\begin{array}{c}\mathrm{C} 0 \\
(\mathrm{n}=12)\end{array}$ & $\begin{array}{c}\mathrm{C} 1 \\
(\mathrm{n}=18)\end{array}$ & $\begin{array}{c}\mathrm{C} 2+\mathrm{C} 3 \\
(\mathrm{n}=16)\end{array}$ & \\
\hline Age (year) & $58.0 \pm 10.0$ & $58.8 \pm 8.6$ & $61.5 \pm 9.4$ & $64.1 \pm 8.5$ & $60.1 \pm 8.5$ \\
\hline Gender (M:F) & $10 / 8$ & $7 / 5$ & $9 / 9$ & $9 / 7$ & $25 / 21$ \\
\hline LAD & 0 & $54.3 \pm 38.2$ & $84.6 \pm 19.5$ & $88.9 \pm 23.5$ & $76.8 \pm 28.4$ \\
\hline LCX & 0 & $24.6 \pm 36.4$ & $48.6 \pm 36.1$ & $52.6 \pm 40.1$ & $46.2 \pm 38.1$ \\
\hline RCA & 0 & $22.2 \pm 32.4$ & $43.6 \pm 34.7$ & $45.9 \pm 45.9$ & $40.5 \pm 38.3$ \\
\hline $\mathrm{TC}(\mathrm{mmol} / \mathrm{l})$ & $4.96 \pm 0.11$ & $4.77 \pm 0.72$ & $4.65 \pm 0.76$ & $4.96 \pm 0.71$ & $4.80 \pm 0.78$ \\
\hline $\mathrm{TG}(\mathrm{mmol} / \mathrm{l})$ & $1.57 \pm 0.10$ & $1.74 \pm 0.91$ & $1.89 \pm 0.81$ & $2.06 \pm 0.71$ & $1.92 \pm 0.86$ \\
\hline LDL (mmol/l) & $2.86 \pm 0.12$ & $2.50 \pm 0.60$ & $2.26 \pm 0.64$ & $2.36 \pm 0.55$ & $2.38 \pm 0.72$ \\
\hline $\mathrm{HDL}(\mathrm{mmol} / \mathrm{l})$ & $1.39 \pm 0.10$ & $1.45 \pm 0.19$ & $1.40 \pm 0.22$ & $1.43 \pm 0.27$ & $1.43 \pm 0.33$ \\
\hline
\end{tabular}

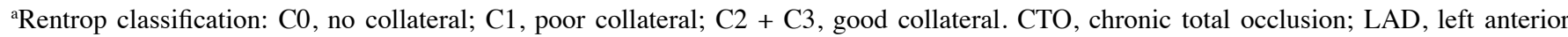
descending; LCX, left circumflex artery; RCA, right coronary artery; TC, total cholesterol; TG, triglyceride; LDL, low-density lipoprotein; HDL, high-density lipoprotein.

A

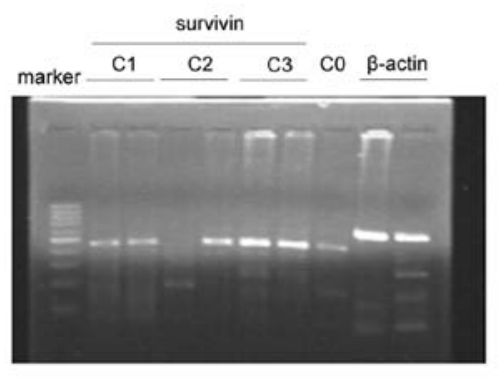

B

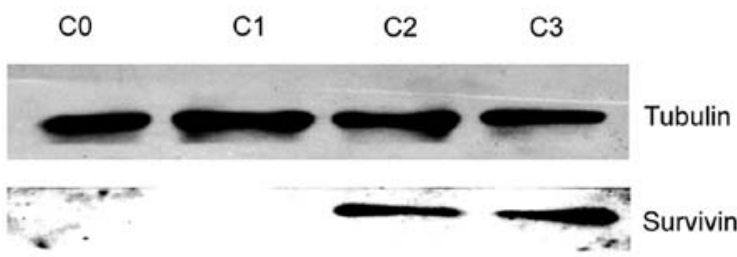

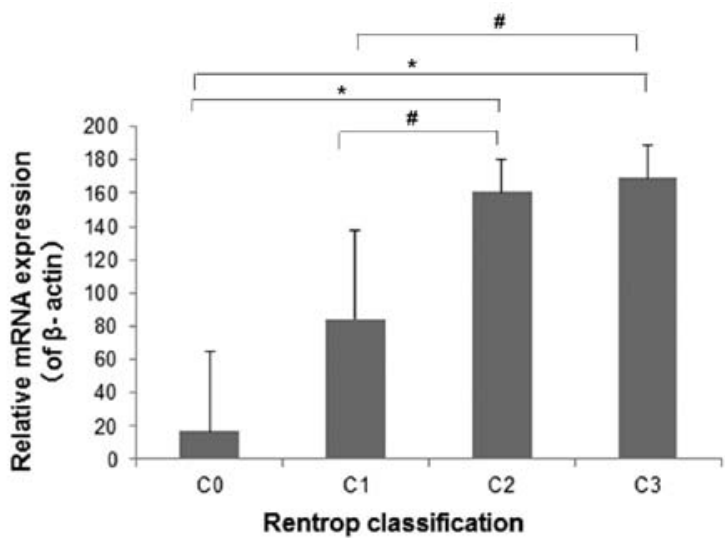

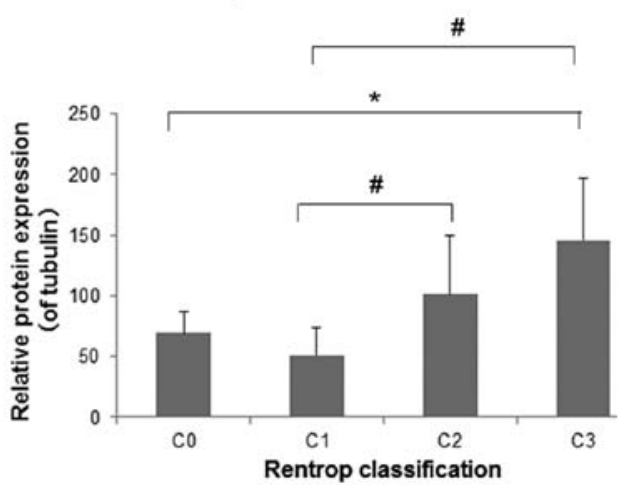

Figure 2. Survivin expression in human peripheral blood mononuclear cells (PBMCs) during coronary collateral formation. (A) Survivin mRNA expression in PBMCs during coronary collateral formation was determined by RT-PCR. $\beta$-actin was used as an internal control. Semi-quantitative analysis mRNA expression of survivin. (B) Survivin protein expression in PBMCs during coronary collateral formation was determined by western blotting. Tubulin was used as an internal control. Semi-quantitative analysis protein expression of survivin. The data are the means \pm standard deviation (SD) of three independent experiments. ${ }^{*} \mathrm{P}<0.05, \mathrm{C} 3+\mathrm{C} 2, \mathrm{C} 1, \mathrm{C} 0$ vs. normal control; ${ }^{"} \mathrm{P}<0.05, \mathrm{C} 3+\mathrm{C} 2, \mathrm{C} 1$ vs. $\mathrm{C} 0 ;{ }^{\wedge} \mathrm{P}<0.05, \mathrm{C} 3+\mathrm{C} 2$ vs. $\mathrm{C} 1$.

Percentages of survivin and CD44 single-positive PMBCs, and survivin + CD8, + VEGF, and + ICAM-1 double-positive PBMCs were observed significantly higher in the GM-CSF treatment group as compared to those observed in the remaining groups (all $\mathrm{P}<0.05)$. Percentages of survivin single-positive PMBCs, and survivin and CD8, VEGF and
ICAM-1 double-positive PBMCs were significantly higher in the operation group than those in the sham-operation and normal control groups (all $\mathrm{P}<0.05$ ) (Fig. 5 and Table III). Furthermore, in specimens with higher survivin levels, significantly larger and more visible collateral vessels were consistently observed. 
Table II. Flow cytometric analysis of survivin and CD44 single-positive, and survivin and CD4, CD8, VEGF and ICAM-1 double-positive in human PBMCs during coronary collateral formation.

\begin{tabular}{lcccccc}
\hline $\begin{array}{l}\text { Rentrop } \\
\text { classification }\end{array}$ & $\begin{array}{c}\text { Survivin } \\
\%\end{array}$ & $\begin{array}{c}\text { Sur +CD4 } \\
\%\end{array}$ & $\begin{array}{c}\text { Sur +CD8 } \\
\%\end{array}$ & $\begin{array}{c}\text { CD44 } \\
\%\end{array}$ & $\begin{array}{c}\text { Sur + VEGF } \\
\%\end{array}$ & $\begin{array}{c}\text { Sur + ICAM-1 } \\
\%\end{array}$ \\
\hline Normal control & $6.2 \pm 2.5$ & $56.1 \pm 6.2$ & $5.1 \pm 2.2$ & $10.6 \pm 4.1$ & $9.0 \pm 3.9$ & $4.4 \pm 2.1$ \\
C0 & $21.6 \pm 10.8^{\mathrm{a}}$ & $38.4 \pm 6.8^{\mathrm{a}}$ & $4.4 \pm 0.9$ & $17.5 \pm 5.7$ & $19.5 \pm 4.6^{\mathrm{a}}$ & $5.0 \pm 1.4$ \\
C1 & $19.7 \pm 15.9$ & $37.2 \pm 8.6^{\mathrm{a}}$ & $3.8 \pm 1.5$ & $31.1 \pm 8.3^{\mathrm{a}, \mathrm{b}}$ & $34.7 \pm 8.6^{\mathrm{a}, \mathrm{b}}$ & $3.0 \pm 1.1^{\mathrm{b}}$ \\
C2 \pm C3 & $45.0 \pm 16.2^{\mathrm{a}-\mathrm{c}}$ & $31.9 \pm 7.4^{\mathrm{a}}$ & $36.5 \pm 5.1^{\mathrm{a}-\mathrm{c}}$ & $65.4 \pm 8.2^{\mathrm{a}-\mathrm{c}}$ & $54.6 \pm 6.2^{\mathrm{a}-\mathrm{c}}$ & $21.4 \pm 5.4^{\mathrm{a}-\mathrm{c}}$ \\
\hline
\end{tabular}

Data are the means $\pm \mathrm{SD}$ of three independent experiments. ${ }^{\mathrm{a}} \mathrm{P}<0.05, \mathrm{C} 3+\mathrm{C} 2, \mathrm{C} 1, \mathrm{C} 0$ vs. normal control; ${ }^{\mathrm{b}} \mathrm{P}<0.05, \mathrm{C} 3+\mathrm{C} 2, \mathrm{C} 1 \mathrm{vs} . \mathrm{C} 0$; ${ }^{\mathrm{P}}<<0.05$, C3 + C2 vs. C1. PBMCs, peripheral blood mononuclear cells; SD, standard deviation; VEGF, vascular endothelial growth factor; ICAM-1, intercellular adhesion molecule-1.
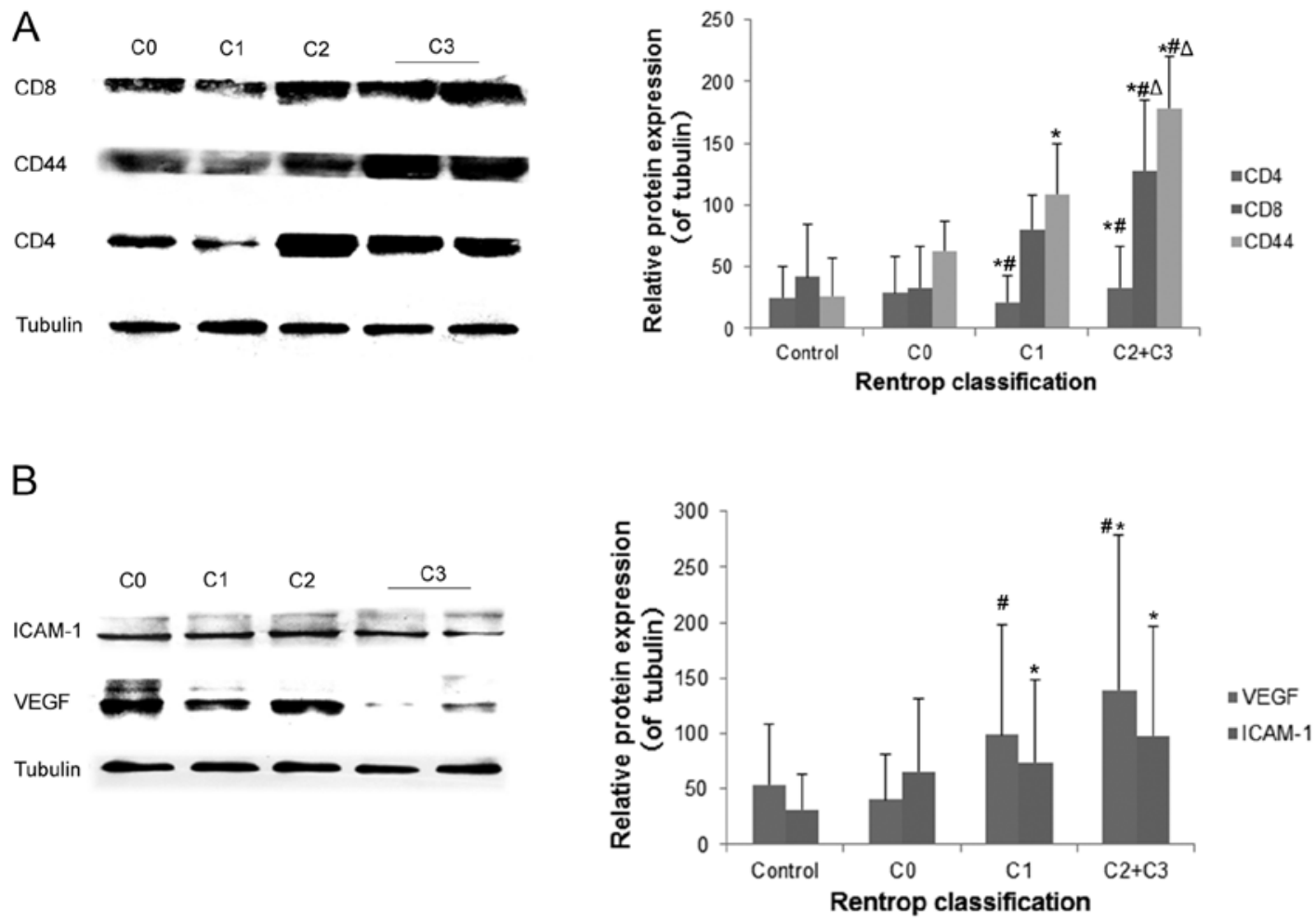

Figure 3. CD4, CD8, CD44, vascular endothelial growth factor (VEGF) and intercellular adhesion molecule-1 (ICAM-1) expression in human peripheral blood mononuclear cells (PBMCs) during coronary collateral formation. CD4, CD8, CD44, VEGF and ICAM-1 expression was determined by western blotting. Tubulin was used as an internal control. (A) CD4, CD8 and CD44 protein expression and (B) VEGF and ICAM-1 protein expression. The data are the means $\pm \mathrm{SD}$ of three independent experiments. ${ }^{*} \mathrm{P}<0.05, \mathrm{C} 3+\mathrm{C} 2, \mathrm{C} 1, \mathrm{C} 0$ vs. normal control; ${ }^{*} \mathrm{P}<0.05, \mathrm{C} 3+\mathrm{C} 2, \mathrm{C} 1$ vs. $\mathrm{C} 0 ;{ }^{\wedge} \mathrm{P}<0.05, \mathrm{C} 3+\mathrm{C} 2$ vs. $\mathrm{C} 1$.

\section{Discussion}

Increased survivin expression in PBMCs was associated with greater coronary collateral formation in CTO patients. Moreover, the flow cytometric analysis revealed that the percentage of survivin-positive PBMCs was significantly higher in patients with good collateral formation than that in patients with poor collateral formation. These findings were confirmed in a rat model of hind limb ischemia, indicating that GM-CSF treatment after femoral artery ligation is capable of significantly promoting collateral formation. Notably, survivin, CD4, CD44 single-positive PBMCs as well as survivin + CD8, + VEGF, and + ICAM-1 double-positive
PBMCs were increased, consistent with findings in samples from human cells. While survivin levels have previously been associated with CAD (4), this novel finding demonstrates that the survivin expression signature of PBMCs may increase collateral formation, potentially providing a valuable prognostic indicator in CAD patients, particularly those with coronary CTO. Furthermore, these observations are potentially useful in developing revascularization strategies.

The role of $\mathrm{CD}^{+}, \mathrm{CD} 8^{+}$and $\mathrm{CD} 44^{+} \mathrm{T}$ lymphocytes in arteriogenesis and collateral development is well documented. Accumulating evidence has indicated that survivin is expressed in normal adult cells, particularly in primitive hematopoietic cells, $\mathrm{T}$ lymphocytes, polymorphonuclear neutrophils, and 
Table III. Flow cytometric analysis for survivin and CD44 single-positive, and survivin and CD4, CD8, VEGF and ICAM-1 double-positive in rat model of hind limb ischemia.

\begin{tabular}{lcccccc}
\hline Group & $\begin{array}{c}\text { Survivin } \\
\%\end{array}$ & $\begin{array}{c}\text { Sur CD4 } \\
\%\end{array}$ & $\begin{array}{c}\text { Sur +CD8 } \\
\%\end{array}$ & $\begin{array}{c}\text { CD44 } \\
\%\end{array}$ & $\begin{array}{c}\text { Sur + VEGF } \\
\%\end{array}$ & $\begin{array}{c}\text { Sur + ICAM-1 } \\
\%\end{array}$ \\
\hline Normal control & $6.3 \pm 2.3$ & $55.2 \pm 6.4$ & $5.3 \pm 2.1$ & $10.0 \pm 4.2$ & $7.8 \pm 3.7$ & $4.8 \pm 2.2$ \\
Sham-operation & $7.1 \pm 2.9$ & $48.4 \pm 7.1$ & $4.8 \pm 1.2$ & $11.5 \pm 5.6$ & $10.7 \pm 2.3$ & $4.8 \pm 1.3$ \\
Operation & $16.9 \pm 6.1^{\mathrm{a}, \mathrm{b}}$ & $35.8 \pm 7.7^{\mathrm{a}, \mathrm{b}}$ & $5.9 \pm 5.3$ & $30.1 \pm 7.5^{\mathrm{a}, \mathrm{b}}$ & $25.1 \pm 7.5^{\mathrm{a}, \mathrm{b}}$ & $3.3 \pm 1.1$ \\
GM-CSF & $40.5 \pm 13.1^{\mathrm{a}-\mathrm{c}}$ & $42.5 \pm 7.4^{\mathrm{a}}$ & $33.7 \pm 7.4^{\mathrm{a}-\mathrm{c}}$ & $50.5 \pm 7.0^{\mathrm{a}-\mathrm{c}}$ & $52.0 \pm 9.0^{\mathrm{a}-\mathrm{c}}$ & $20.5 \pm 5.8^{\mathrm{a}-\mathrm{c}}$ \\
\hline
\end{tabular}

Data are the means \pm SD of three independent experiments. ${ }^{\mathrm{a}} \mathrm{P}<0.05, \mathrm{GM}-\mathrm{CSF}$, operation, sham-operation vs. normal control; ${ }^{\mathrm{b}} \mathrm{P}<0.05, \mathrm{GM}-\mathrm{CSF}$, operation vs. sham-operation; ${ }^{\mathrm{C}} \mathrm{P}<0.05$, GM-CSF vs. operation. GM-CSF, granulocyte macrophage colony-stimulating factor; VEGF, vascular endothelial growth factor; ICAM-1, intercellular adhesion molecule-1.

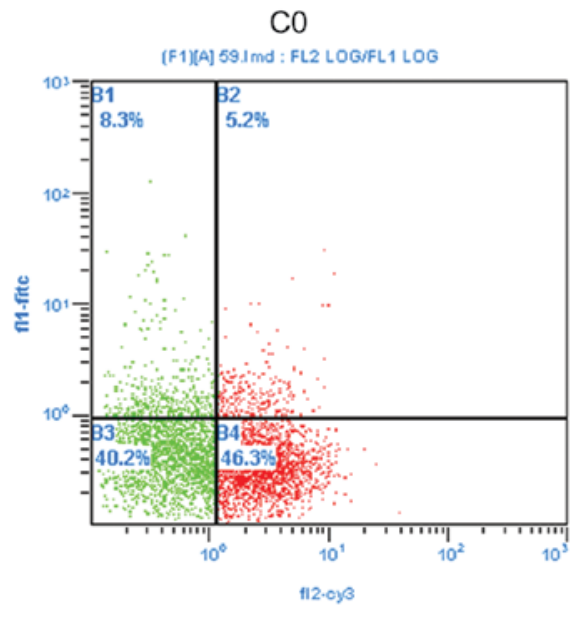

$\mathrm{C} 2$

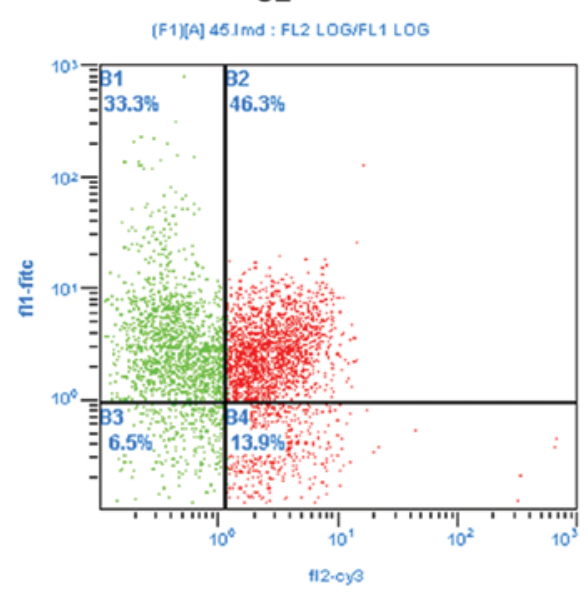

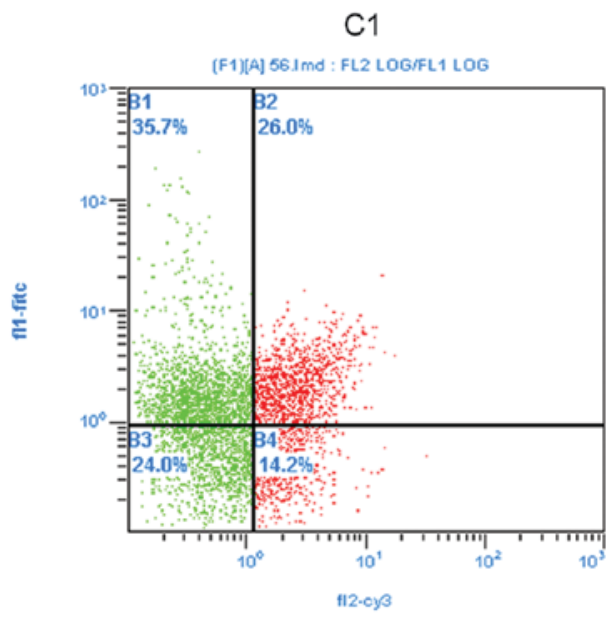

C3

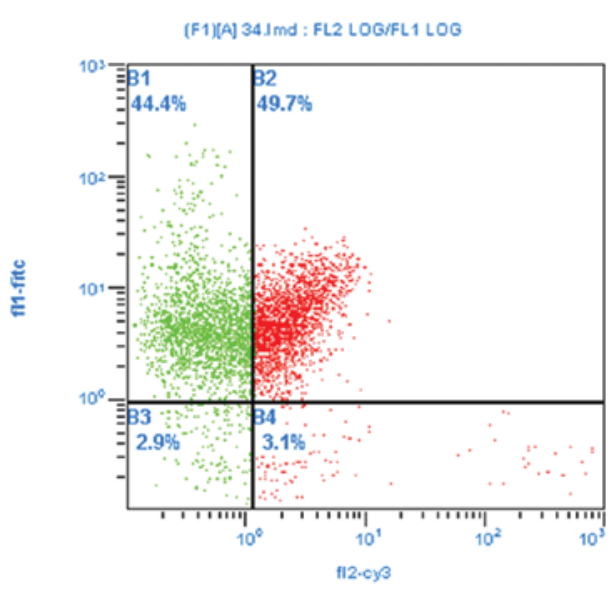

Figure 4. Flow cytometric analysis for survivin (FITC, green) + vascular endothelial growth factor (VEGF) (Cy3, red) double-positive in human peripheral blood mononuclear cells (PBMCs) during coronary collateral formation.

vascular endothelial cells, where it is important in cell proliferation, regulation, and survival (20). $\mathrm{CD}^{+} \mathrm{T}$ cells control the arteriogenic response to acute hind limb ischemia, in part by recruiting macrophages to the site of active collateral artery formation and triggering the development of collateral arteries through arteriogenic cytokine synthesis (21). During collateral formation, $\mathrm{CD}^{+} \mathrm{T}$ cells contribute to the early phases of collateral development. Following femoral artery ligation,
$\mathrm{CD}^{+} \mathrm{T}$ cells infiltrate the site of collateral vessel growth and recruit $\mathrm{CD}^{+}$mononuclear cells by expressing IL-16 (21). Notably, CD44 deficiency has been reported to impede arteriogenesis (22), and increased CD44 expression on isolated monocytes is increased in patients with good collateralization (23). Confirming these findings, Arslan et al (24) reported a significant association between increased circulating $\mathrm{CD}^{+}+\mathrm{CD}^{+} 6^{-}$monocyte levels and good coronary collateral 


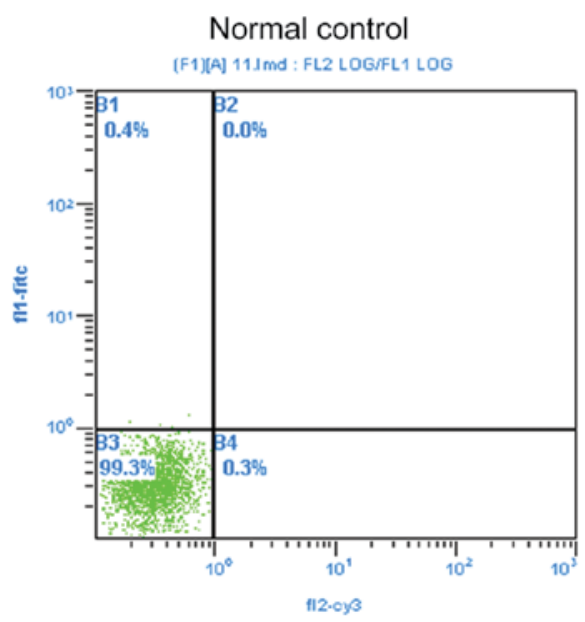

Operation

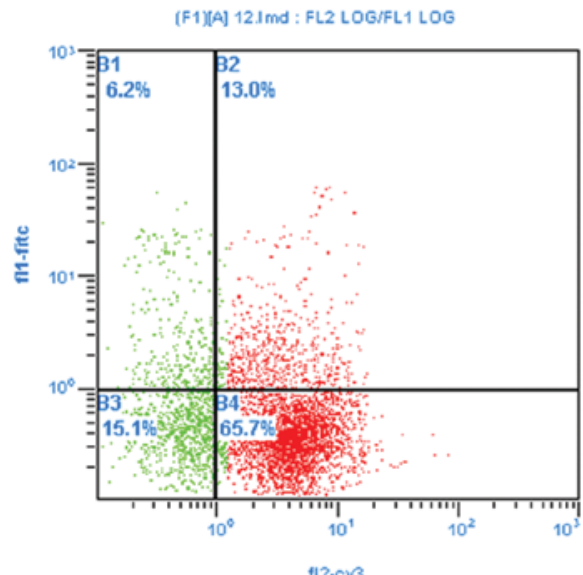

Sham-operation

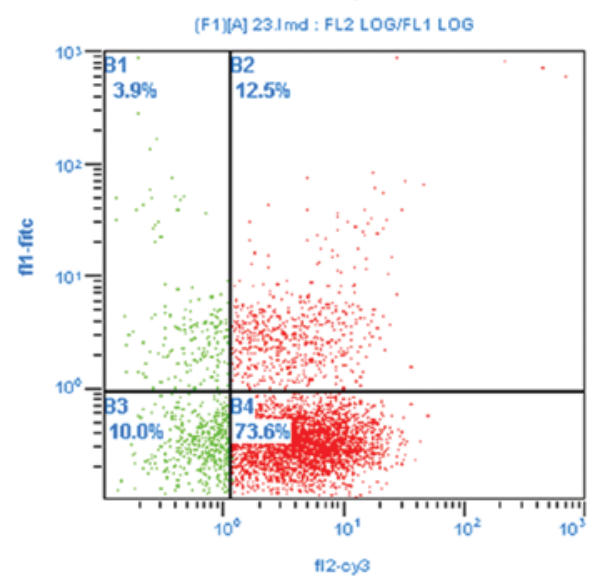

GM-CSF

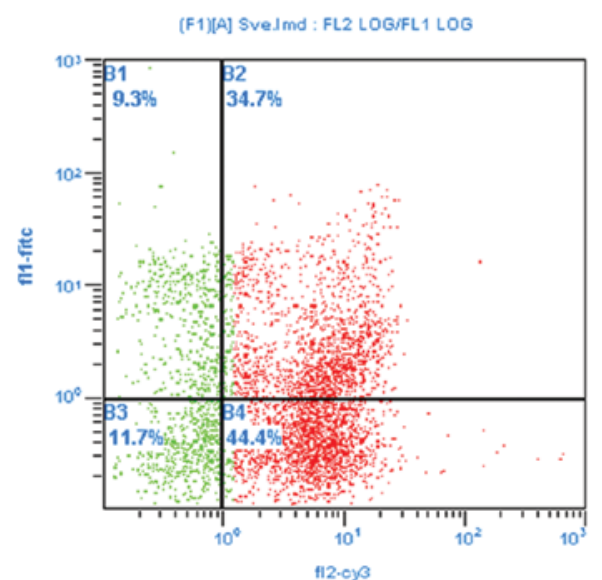

Figure 5. Flow cytometric analysis of survivin (FITC, green) + vascular endothelial growth factor (VEGF) (Cy3, red) double-positive in rat model of hind limb ischemia.
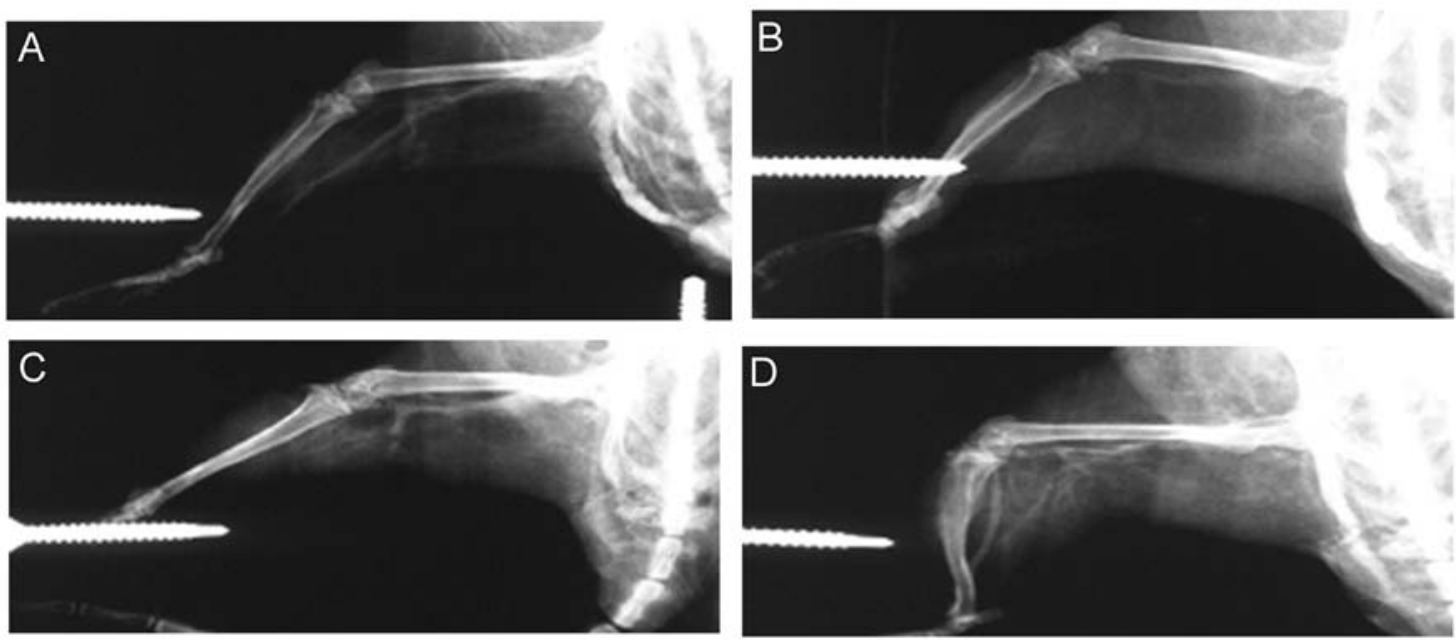

Figure 6. Collateral artery growth in postmortem angiography in rat model of hind limb ischemia. Angiograms in the (A) normal control and (B) operation groups revealed very poor collateral formation, whereas good collateral formation was observed in the (C) granulocye macrophage colony-stimulating factor (GM-CSF) treatment groups at 28 days after operation and (D) GM-CSF treatment groups at 42 days after operation, where collateral was most apparent

development. Those findings are consistent with those of the present findings showing that CD4-, CD8- and CD44-positive $\mathrm{T}$ cells play a crucial role in collateral formation.
Expression of ICAM-1 and/or VEGF is critical to the growth of coronary collaterals $(24,25)$. As shear stress upregulates the expression of endothelial cell adhesion 
receptors such as ICAM-1 and vascular cell adhesion molecule-1 $(26,27)$, monocyte adhesion to shear stress-activated endothelium is important in arteriogenesis and in collateral artery growth (28). Hoefer et al (29) demonstrated that ICAM-1-mediated monocyte adhesion via ICAM-1/Mac-1 interaction to the endothelium of collateral arteries is essential in these processes by treating in vivo subjects with monoclonal antibodies against ICAM-1, which totally abolished the stimulatory effect of MCP-1 on collateral artery growth (30). Similarly, Rivard et al (31) reported that a reduced VEGF expression in diabetic mice resulted in impairment of new blood vessel formation, although cytokine supplementation using intramuscular adeno-VEGF gene transfer restored neovascularization (25). Consistent with the present study, ICAM-1 and VEGF are essential in many vascularization processes, including collateral formation. In particular, the present study demonstrates that expression of VEGF and ICAM-1 was elevated in patients with collateral formation. Furthermore, PBMCs in patients with elevated collateral evidenced distinctly higher rates of survivin single-positive as well as survivin + VEGF and + ICAM-1 double-positive cells, indicating that the mechanism of coronary collateral formation may be, in part, associated with high survivin, VEGF, ICAM-1 expression in PBMCs.

However, it has been shown that VEGF exerts antiapoptotic effects during angiogenesis that may be mediated by the induced survivin expression in endothelial cells (31). Although these findings seem to limit the practical implementation of survivin upregulation, the importance of survivin during vascularization processes, including collateral formation is confirmed. However, the clinical relationships between compounds, such as VEGF and survivin, in human PMBCs merits further investigation prior to development of clinical strategies. It is important to consider also that, this study may be limited by the relatively small study group and use of a hind limb ischemia rat model as compared to the coronary collateral formation model due to the insufficiently small size of the rat coronary artery for contrast-based angiography. Furthermore, the rat hind limb model was selected for comparison with human coronary collateral formation as it has been reported that the femoral artery ligation rat model is simple and accurate for use in angiographic studies, whereas coronary artery ligation in rats is extremely difficult and less accurate $(32,33)$. Thus, the present model has been demonstrated to produce low animal mortality and high success rates in numerous investigations of coronary CTO in the literature $(32,33)$. Despite the use of this established model, any error occurring may be due to the discrepancies between the hind limb ischemia and coronary collateral rat models, which should be considered in the analysis of these results and design of future clinical studies.

In conclusion, in PMBCs from clinical coronary CTO patients and a rat model of hind limb ischemia, an elevated survivin expression in PBMCs, particularly of survivin and CD8, VEGF, ICAM-1 double-positive PBMCs were associated with good collateral formation. Thus, assessment of survivin level in the peripheral blood may provide a viable clinical alternative for CAD assessment. Furthermore, there may be potential applications of these findings in revascularization strategies for treating CAD patients that may undergo ischemic events due to disease or bypass surgery.

\section{References}

1. Seiler C: The human coronary collateral circulation. Heart 89: 1352-1357, 2003.

2. Fefer P, Knudtson ML, Cheema AN, et al: Current perspectives on coronary chronic total occlusions: the Canadian Multicenter Chronic Total Occlusions Registry. J Am Coll Cardiol 59: 991-997, 2012.

3. Petronio AS, Baglini R, Limbruno U, et al: Coronary collateral circulation behaviour and myocardial viability in chronic total occlusion treated with coronary angioplasty. Eur Heart J 19: 1681-1687, 1998.

4. Levkau B, Schäfers M, Wohlschlaeger J, et al: Survivin determines cardiac function by controlling total cardiomyocyte number. Circulation 117: 1583-1593, 2008.

5. Hoekstra M, van der Lans CA, Halvorsen B, et al: The peripheral blood mononuclear cell microRNA signature of coronary artery disease. Biochem Biophys Res Commun 394: 792-797, 2010.

6. Zhen HN, Zhang X, Hu PZ, et al: Survivin expression and its relation with proliferation, apoptosis, and angiogenesis in brain gliomas. Cancer 104: 2775-2783, 2005.

7. O'Connor DS, Schechner JS, Adida C, et al: Control of apoptosis during angiogenesis by survivin expression in endothelial cells. Am J Pathol 156: 393-398, 2000.

8. Lee GH, Joo YE, Koh YS, et al: Expression of survivin in gastric cancer and its relationship with tumor angiogenesis. Eur J Gastroenterol Hepatol 18: 957-963, 2006.

9. Zwerts F, Lupu F, De Vriese A, et al: Lack of endothelial cell survivin causes embryonic defects in angiogenesis, cardiogenesis, and neural tube closure. Blood 109: 4742-4752, 2007.

10. Waksman R, Saito S, Galassi AR and Tomasello SD: Collateral circulation in CTO. In: Chronic Total Occlusions: A Guide to Recanalization. Waksman R and Saito S (eds). John Wiley and Sons, Oxford.

11. Conway EM, Zwerts F, Van Eygen V, et al: Survivin-dependent angiogenesis in ischemic brain: molecular mechanisms of hypoxia-induced up-regulation. Am J Pathol 163: 935-946, 2003.

12. Cotton JM, Mathur A, Hong Y, Brown AS, Martin JF and Erusalimsky JD: Acute rise of circulating vascular endothelial growth factor-A in patients with coronary artery disease following cardiothoracic surgery. Eur Heart J 23: 953-959, 2002.

13. Labarrere CA, Nelson DR, Miller SJ, et al: Value of serumsoluble intercellular adhesion molecule-1 for the noninvasive risk assessment of transplant coronary artery disease, posttransplant ischemic events, and cardiac graft failure. Circulation 102: $1549-1555,2000$

14. Teeuwen K, Adriaenssens T, Van den Branden BJ, et al: A randomized multicenter comparison of hybrid sirolimus-eluting stents with bioresorbable polymer versus everolimus-eluting stents with durable polymer in total coronary occlusion: rationale and design of the Primary Stenting of Occluded Native Coronary Arteries IV study. Trials 13: 240, 2012.

15. Rentrop KP, Cohen M, Blanke H and Phillips RA: Changes in collateral channel filling immediately after controlled coronary artery occlusion by an angioplasty balloon in human subjects. J Am Coll Cardiol 5: 587-592,1985.

16. Kato M, Shiode N, Yamagata T, Matsuura H and Kajiyama G: Coronary segmental responses to acetylcholine and bradykinin in patients with atherosclerotic risk factors. Am J Cardiol 80: 751-755, 1997.

17. Xu YG, Zhou SH, Li YG, et al: The mechanism underlying vascular smooth muscle cell apoptosis induced by atorvastatin may be mainly associated with down-regulation of survivin expression. Cardiovasc Drugs Ther 21: 145-153, 2007.

18. Lee CW, Stabile E, Kinnaird T, et al: Temporal patterns of gene expression after acute hindlimb ischemia in mice: insights into the genomic program for collateral vessel development. J Am Coll Cardiol 43: 474-482, 2004.

19. Yu J, deMuinck ED, Zhuang Z, et al: Endothelial nitric oxide synthase is critical for ischemic remodeling, mural cell recruitment, and blood flow reserve. Proc Natl Acad Sci USA 102: 10999-11004, 2005.

20. Fukuda S and Pelus LM: Survivin, a cancer target with an emerging role in normal adult tissues. Mol Cancer Ther 5: 1087-1098, 2006.

21. Stabile E, Burnett MS, Watkins C, et al: Impaired arteriogenic response to acute hindlimb ischemia in CD4-knockout mice. Circulation 108: 205-210, 2003. 
22. Stabile E, Kinnaird T, la Sala A, et al: $\mathrm{CD} 8^{+} \mathrm{T}$ lymphocytes regulate the arteriogenic response to ischemia by infiltrating the site of collateral vessel development and recruiting CD4 ${ }^{+}$ mononuclear cells through the expression of interleukin-16. Circulation 113: 118-124, 2006.

23. van Royen N, Voskuil M, Hoefer I, et al: CD44 regulates arteriogenesis in mice and is differentially expressed in patients with poor and good collateralization. Circulation 109: 1647-1652, 2004.

24. Arslan U, Kocaoğlu I, Falay MY, Balci M, Duyuler S and Korkmaz A: The association between different monocyte subsets and coronary collateral development. Coron Artery Dis 23: 16-21, 2012.

25. Zentilin L, Tafuro S, Zacchigna S, et al: Bone marrow mononuclear cells are recruited to the sites of VEGF-induced neovascularization but are not incorporated into the newly formed vessels. Blood 107: 3546-3554, 2006.

26. Hong $\mathrm{KH}$, Ryu J and Han $\mathrm{KH}$ : Monocyte chemoattractant protein-1-induced angiogenesis is mediated by vascular endothelial growth factor-A. Blood 105: 1405-1407, 2005.

27. Gimbrone MA Jr, Nagel T and Topper JN: Biomechanical activation: an emerging paradigm in endothelial adhesion biology. $\mathrm{J}$ Clin Invest 99: 1809-1813, 1997.
28. Toyota E, Warltier DC, Brock T, et al: Vascular endothelial growth factor is required for coronary collateral growth in the rat. Circulation 112: 2108-2113, 2005.

29. Hoefer IE, van Royen N, Rectenwald JE, et al: Arteriogenesis proceeds via ICAM-1/Mac-1-mediated mechanisms. Circ Res 94: 1179-1185, 2004

30. Scholz D, Ito W, Fleming I, et al: Ultrastructure and molecular histology of rabbit hind-limb collateral artery growth (arteriogenesis). Virchows Arch 436: 257-270, 2000.

31. Rivard A, Silver M, Chen D, et al: Rescue of diabetes-related impairment of angiogenesis by intramuscular gene therapy with adeno-VEGF. Am J Pathol 154: 355-363, 1999.

32. Heil M, Ziegelhoeffer T, Pipp F, et al: Blood monocyte concentration is critical for enhancement of collateral artery growth. Am J Physiol Heart Circ Physiol 283: H2411-H2419, 2002.

33. Heil M, Ziegelhoeffer T, Wagner S, et al: Collateral artery growth (arteriogenesis) after experimental arterial occlusion is impaired in mice lacking CC-chemokine receptor-2. Circ Res 94: 671-677, 2004 